\title{
AVALIAÇÃO PATOLÓGICA DA CAPELA NOSSO SENHOR DOS PASSOS EM CÓRREGOS/MG
}

\author{
TEODORO, BRENDA GABRIELLE DE P. \\ Estudante \\ Centro Universitário UNA \\ Minas Gerais; Brasil \\ brendagabriellepaula@gmail.com
}

LOPES, PEDRO HENRIQUE CAETANO R.

Estudante

Centro Universitário UNA

Minas Gerais; Brasil

pedrohcr20@gmail.com

\author{
ANTUNES, MICHELLE APARECIDA \\ Estudante \\ Centro Universitário UNA \\ Minas Gerais; Brasil \\ michellea.antunes@hotmail.com
}

\author{
SILVA, LARISSA CAMILO DE S. LIMA E \\ Docente \\ Centro Universitário UNA \\ Minas Gerais; Brasil \\ larissa.silva@prof.una.br
}

\section{RESUMO}

As manifestações patológicas podem se fazer presentes em qualquer edificação, quer seja pelo processo executivo, especificação errônea de materiais e até mesmo com o passar do tempo devido à ausência de manutenção ou o uso inadequado do imóvel. O método utilizado para a correção destas deformações plásticas está diretamente relacionado a qual tipo de construção se trata, de modo que, quando a obra em questão for um patrimônio tombado, faz-se necessário a utilização da técnica de restauro, que visa a recuperação dos danos mantendo as características, identidade e autenticidade da época em que a edificação fora construída. Portanto, com base no processo de restauração da Capela Nosso Senhor de Passos, no distrito de Córregos-MG, o presente artigo acadêmico apresenta o mapeamento de danos e as propostas de intervenção das deformações plásticas identificadas, de modo a considerar os problemas patológicos em um imóvel tombado, tendo em vista que o objeto de estudo é um bem cultural protegido pelo Instituto Estadual do Patrimônio Histórico e Artístico de Minas Gerais.

Palavras-chave: manifestações patológicas, mapeamento de danos, patrimônio tombado, restauro.

\begin{abstract}
Pathological manifestations can be found in any building, whether due to the executive process, erroneous specification of materials or even due to lack of maintenance or improper use of the property. The way these plastic deformations are corrected is directly related to what kind of construction it is, so, when the work in question is a listed patrimony it is necessary to use the restoration technique, which aims at damage repair while maintaining the features, identity and authenticity of the period when the building was built. Therefore, based on the process of restoration of the Capela de Nosso Senhor de Passos, in the district of Córregos - MG, this academic article aims to elaborate the damage mapping and the intervention proposals of the identified plastic deformations, in order to consider the pathological problems presented. in a listed property), considering that the object of study is a cultural property protected by Instituto Estadual do Patrimônio Histórico e Artístico de Minas Gerais.
\end{abstract}

Keywords: pathological manifestations, damage mapping, fallen heritage, restoration.

\section{INTRODUÇÃO}

A ocorrência de manifestações patológicas ocasiona uma redução da vida útil da edificação, sendo diretamente relacionada ao desempenho de seus componentes. De modo geral, esses problemas são evolutivos e tendem a se intensificar com o passar do tempo, além de acarretarem outros danos associados ao problema inicial, que podem estar relacionados a aspectos de ordem intrínseca provenientes dos materiais que constituem a edificação, ou extrínseca devido a fatores externos aos mesmos. (LIMA, et al. 2014, p. 1.716)

Silva (2017, p.02) ainda destaca que quando uma manifestação patológica ocorre em um edifício histórico, pode comprometer não apenas a durabilidade daquele sistema, mas provocar a descaracterização do patrimônio e afetar, diretamente, na história local daquela região à qual ele está inserido. 
Segundo Mukai (2003, p.37), a degradação ao patrimônio pode esta relacionada a três fatores: a escassa vigilância do Poder Público na fiscalização dos bens tombados; a dificuldade de preservação dos objetos e imóveis tombados; e a inação do Poder Público (Executivo) quanto a tombamentos de bens que contenham valor histórico, paisagístico, arqueológico, histórico e/ou cultural.

Deste modo, a valorização do patrimônio histórico é de extrema importância, pois segundo o Art. $1^{\circ}$, do Decreto-lei $\mathrm{n}^{\mathrm{o}}$ 25, de 30 de novembro de 1937 (Brasil, 1937), seu conceito é constituído como o conjunto dos bens móveis e imóveis existentes no país cuja conservação seja de interesse público, quer por sua vinculação a fatos memoráveis da história do Brasil, quer por seu excepcional valor arqueológico ou etnográfico, bibliográfico ou artístico.

Por meios legais, torna-se possível declarar o valor histórico de um patrimônio, de modo a protegê-lo e preservá-lo, através do tombamento, que entende-se como um "ato administrativo realizado pelo poder público (SEEC/CPC) com objetivo de preservar, através da aplicação da lei, bens de valor histórico, cultural, arquitetônico e ambiental para a população, impedindo que venham a ser destruídos ou descaracterizados". (CABRAL, 2017, p.77)

Porém, no Brasil, a preservação, conservação e repressão aos delitos cometidos contra o nosso patrimônio é quase inexistente. Pois, embora os órgãos e/ou entidades da União, dos Estados e de alguns municípios se esforcem no cumprimento de suas missões, geralmente os mesmos não dispõe de respaldo financeiro e pessoal para uma eficaz proteção. (MUKAI, 2003, p.37)

Diante do exposto, o presente artigo acadêmico apresenta, o mapeamento de danos e as propostas de intervenção das deformações plásticas que foram identificadas, em uma obra de restauro de patrimônio histórico tombado, do IEPHA/MG, com o intuito de contribuir no avanço do conhecimento dos profissionais que atuam na restauração de bens edificados. A obra em questão trata-se da Capela de Nosso Senhor dos Passos, situada no distrito de Córregos em Conceição do Mato Dentro, Minas Gerais.

\section{REFERENCIAL TEÓRICO}

"O termo patrimônio originou-se da palavra pater, que significa pai ou paterno. O patrimônio representava, como ainda representa, os bens de herança que são transmitidos aos filhos”. (MURGUIA e YASSUDA, 2007, p.67)

Somente a partir da Revolução Francesa, que se tem a efetivação da preservação dos bens culturais socialmente definida, pois o Estado assume a sua proteção e, através da ordenação jurídica, os institui e delimita oficialmente, regulamentando o seu uso, a finalidade e o caráter desses bens dentro de leis específicas de propriedade, zoneamento, uso e ocupação do solo. (MILET, 1988 apud FONSECA, 1997, p.54, citado por MURGUIA e YASSUDA, 2007, p.68)

O primeiro registro de uma citação a respeito de patrimônio histórico e artístico no Brasil fora encontrado no Art. 148 da Constituição da República dos Estados Unidos do Brasil de 1934: “Cabe à União, aos Estados e Municípios favorecer e animar o desenvolvimento das ciências, das artes, das letras e da cultura em geral, proteger os objetos de interesse histórico e o patrimônio artístico do país, bem como prestar assistência ao trabalhador intelectual". (ESTADOS UNIDOS DO BRASIL, 1934)

Em 13 de janeiro de 1937, por meio da lei no 378, houve a criação do Serviço do Patrimônio Histórico e Artístico Nacional (SPHAN), cujo os objetivos para a criação do mesmo foram descritos no Art. 46: "fica criado o Serviço do Patrimônio Histórico e Artístico Nacional, com a finalidade de promover, em todo o País e de modo permanente, o tombamento, a conservação, o enriquecimento e o conhecimento do patrimônio histórico e artístico nacional”.

A partir da década de 1970, período em que o regimento político no Brasil era a Ditatura, iniciou-se um movimento de descentralização no controle da fiscalização da proteção dos bens culturais, e desta maneira foi sugerido a criação de entidades regidas por estados e municípios para a realização deste controle. Por meio da lei n $^{\circ} 57757$, de 30 de setembro de 1971, foi criado o IEPHA/MG, uma entidade jurídico-administrativa, cuja finalidade de criação era, em um contexto geral, "exercer a proteção, no território do Estado de Minas Gerais, aos bens móveis e imóveis, de propriedade pública ou particular, de que tratam o Decreto-Lei Federal n 25, de 30 de novembro de 1937, e legislação posterior”.

A proteção e preservação legal de um patrimônio histórico, através da legislação vigente do país, é requerida por meio do processo de tombamento. Segundo Meirelles $(1985$, p.1), “o tombamento é a declaração pelo poder público do valor 
histórico, artístico, paisagístico, turístico, cultural ou científico de coisas que, por essa razão, devem ser preservadas de acordo com a inscrição no livro próprio".

A partir do aprimoramento dos conceitos de restauro pós Segunda Guerra, foram criadas várias associações, tais como o International Institute for Conservation of Historic Objects and Works of Art (IIC), em 1950, e o United Kingdom Institute for Conservation (UKIC), em 1953, com o intuito de estabelecer diversos elementos regulamentadores da área de conservação/restauro e protetores dos bens culturais, levando em consideração Cartas de Restauro já existentes, como as Cartas de Atenas (1931), de Veneza (1964) e da Itália (1987), que foram as mais importantes para contribuir com a consolidação científica da Conservação Preventiva, concentrando sua ênfase "na importância de equilibrar a necessidade do uso, da compreensão e da apreciação do patrimônio cultural”. ELIAS (2002, p. 39), citado por Caldeira (2006, p. 95)

Com o objetivo de fornecer diretrizes gerais para a conservação e restauro estrutural das construções históricas, o ICOMOS (2003) recomenda uma metodologia de avaliação estrutural baseada em quatro etapas fundamentais, sendo elas: 1) análise documental, 2) caracterização estrutural, 3) diagnóstico e 4) adoção de medidas de intervenção. Cabe ressaltar ainda que, este documento recomenda adotar os materiais estruturais, as técnicas tradicionais de construção, bem como os elementos decorativos e arquitetônicos do imóvel, caso seja necessário a realização de intervenções. (MESQUITA, et al, 2015, p. 05)

\subsection{Manifestações patológicas}

A palavra patologia deriva do grego, Phatos significa doença e, Logos significa estudo. Deste modo, o dicionário Michaelis, nova edição - 1913, define a palavra como, a "Ciência, que trata da origem, sintomas e natureza das doenças". O termo relacionado a engenharia civil, estuda os problemas dos edifícios e as alterações funcionais causadas no mesmo. Existe uma diferenciação de conceitos entre patologia e manifestações patológicas, sendo respectivamente, a ciência que, através de um conjunto de teorias busca explicar os mecanismos e as possíveis causas para o aparecimento de uma manifestação patológica, enquanto o segundo significa um mecanismo de degradação. (OLIVEIRA, 2012, p.09)

Segundo Deutsch (2013), citado por Lima (2017, p.12), “as patologias em edificações podem ter origens diferenciadas. Fatores endógenos, exógenos, funcionais e naturais podem interferir e gerar diversos problemas. Problemas estes, oriundos de projeto, da fase do processo executivo, da especificação indevida de materiais, ou podem aparecer com o passar do tempo devido à ausência de manutenção ou uso inadequado".

As manifestações patológicas podem ser atribuídas por duas causas principais: agentes bióticos, que segundo Brito e Calil Jr. (2013, p.04), são seres vivos, tais como bactérias, fungos, insetos e perfuradores marinhos, e suas ações estão condicionadas a fatores de sobrevivência, como umidade, oxigênio, temperatura e fonte de alimento; e agentes abióticos, onde Brito (2014, p.96) explica que as manifestações patológicas são causadas por agentes não vivos, como condicionantes físicos, manutenções inadequadas, condicionantes químicos, anomalias e fatores climáticos.

\subsection{Arquitetura Mineira}

Buscando, como pretexto principal, a busca por índios para abastecer o mercado de mão de obra açucareira do nordeste, as bandeiras comandadas pelos paulistas adentraram no território do atual estado de Minas Gerais e, no ano de 1698, a bandeira de Antonio Dias, descobriu ouro às margens do rio Tripuí, ao pé do pico Itacolomi, onde se localiza atualmente a cidade de Ouro Preto. Desta forma, os arraiás cresceram e novos arraiás foram fundados, permitindo o início do desenvolvimento da arquitetura no estado de Minas. (LEMOS, 1979, citado por OLIVEIRA, 2008, p. 21)

Em meados de 1720 a população era organizada administrativamente em vilas e freguesias, e o maior monumento era a Igreja Matriz, considerada símbolo do poder religioso, sendo construídas em taipa até meados do século XVIII. E o uso de alvenaria de pedra nas construções religiosas teve seu início a partir de 1740, possibilitando o avanço estético com a movimentação curvilínea das plantas e o tratamento ornamental das fachadas principais. (OLIVEIRA, 2008, p. 21)

Segundo Araújo (2002), citado por Oliveira (2008, p. 27), as técnicas construtivas trazidas para o Brasil possuíam basicamente duas vertentes: uma popular, representada pelos Mestres de Ofício e outra erudita, representada pelos Engenheiros Militares.

A Capela Curial São Francisco de Assis, popularmente conhecida como Igrejinha da Pampulha fora projetada, juntamente com outras edificações, de modo a compor o Conjunto Moderno da Pampulha, pelo arquiteto Oscar Niemeyer, com 
paisagismo de Burle Marx e painéis do pintor Cândido Portinari. Inaugurada no ano de 1943, segundo UNESCO (2016), a igreja se destaca entre as obras do complexo pelo casamento harmônico da arquitetura e estrutura: como seus elementos arquitetônicos ganham forma com a própria estrutura em concreto armado, concluída a estrutura, estaria presente a arquitetura.

A Igreja bem como os demais componentes do Conjunto Moderno da Pampulha teve seu tombamento pelo IPHAN Instituto do Patrimônio Histórico e Artístico Nacional, no ano de 1984 e, no ano de 2016 foram reconhecidas como Patrimônio Cultural da Humanidade pela UNESCO - Organização das Naçoes Unidas para a Educação, a Ciência e a Cultura, ato este que contribuiu para a realização do processo de restauro, porém pouco tempo após a construção o revestimento da cobertura da nave principal já apresentava sérios problemas que comprometiam a beleza e a segurança do monumento. (STARLING, 2018, p. 13)

O processo de restauro da Igreja durou 1 ano e meses e teve seu fim com a reinauguração da mesma no dia 04 de outubro de 2019. O restauro fora realizado pela Construtora Tecnibras e, como intervenções, pode-se citar a recuperação do revestimento externo das pastilhas cerâmicas, a pintura, a revitalização do piso, a impermeabilização, a modernização das instalações elétricas e a substituição do forro de madeira da nave central (danificado por conta das infiltrações). (BARATTO, 2019, p. 01)

\section{METODOLOGIA}

\subsection{Estudo de caso}

O presente artigo foi embasado no processo de restauro da Capela Nosso Senhor dos Passos, bem cultural protegido pelo IEPHA-MG, de modo a considerar os problemas patológicos apresentados em um imóvel tombado, que integra o núcleo histórico de Córregos, conforme figura 1. A obra em questão foi realizada pela empresa Anima Conservação Restauração e Artes Eirelli - EPP, contratada e acompanhada pelo IEPHA-MG em 2019, por meio de uma medida compensatória da empresa Anglo American.

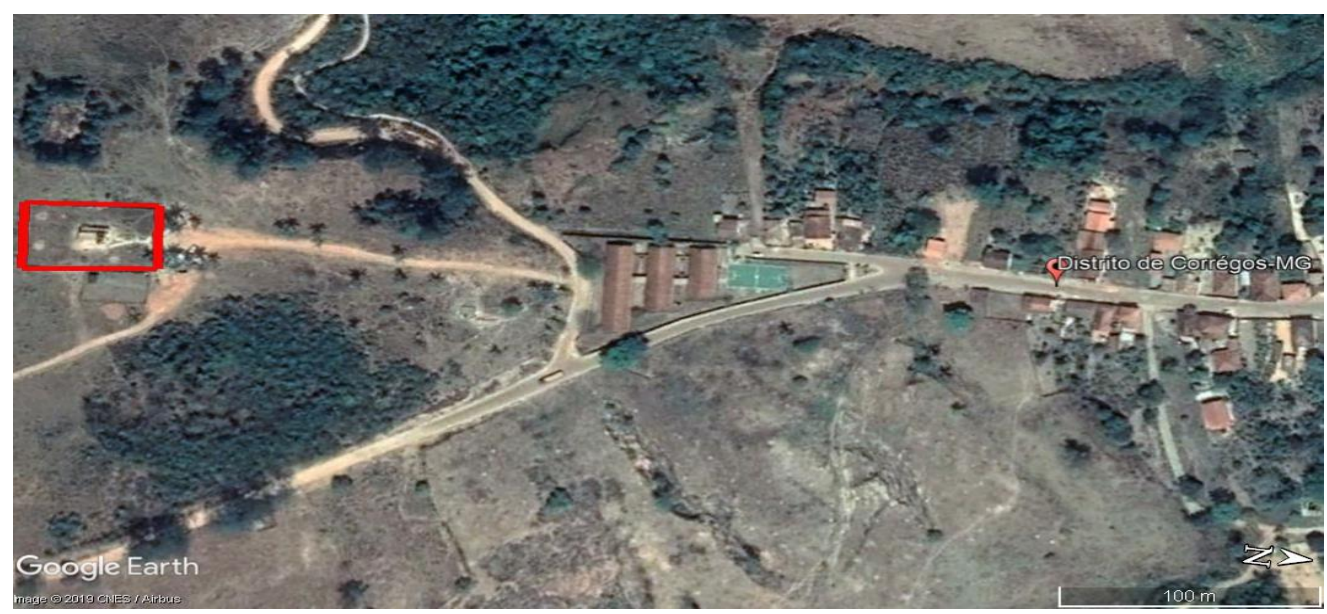

Figura 1: Vista superior de localização da Capela de Nosso Senhor dos Passos.

Fonte: Google Earth, 2019.

A edificação de 103,89 $\mathrm{m}^{2}$, cercada por muro de pedras, evidencia um estilo arquitetônico característico do século XVIII, que demonstra a antiguidade dessa edificação, apesar da carência de qualquer registro ou documentação que lhe faça referência histórica. Apresenta estrutura arquitetônica única que lembra um pequeno templo oriental ou pagode, composta apenas de uma nave central, com frontão em telhas, porta almofadada, duas janelas ladeando o pequeno óculo no nível do coro e corredores laterais que apresentam a peculiaridade de possuírem as paredes internas abertas à meia altura. Está localizada vantajosamente em uma esplanada no ponto mais alto do distrito, na Alameda da Saudade, s/n, distrito de Córregos, em Conceição do Mato Dentro, onde também se localiza o cemitério local.

Em relação ao seu sistema construtivo, pode-se descrever que a mesma é constituída em estrutura autônoma de madeira composta por esteios, baldrames, madres, frechais e ombreira, e vedações em adobe, com algumas intervenções de tijolo cerâmico e piso cimentado, tendo sido um pouco alterada durante as reformas pelas quais passou. As telhas são em barro 
artesanal, tipo “capa e canal”, instaladas sobre engradamento de madeira. As esquadrias são de madeira, sendo com vergas alteadas no setor do frontispício.

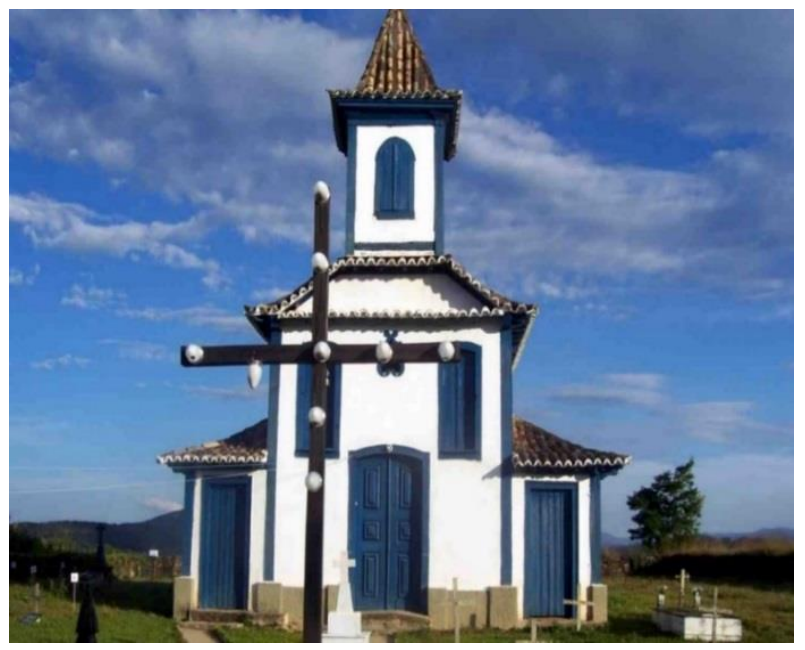

Figura 02 - Vista da Capela de Nosso Senhor dos Passos.

Fonte: IEPHA-MG, 2017

A Capela de Nosso Senhor dos Passos, tombada pelo decreto ${ }^{\circ} 24.329$, de 22 de março de 1985, sendo inscrita no Livro de Tombo $\mathrm{n}^{\circ}$ III - Histórico, das Obras de Arte Históricas e dos Documentos Paleográficos ou Bibliográficos, está localizada a $25 \mathrm{Km}$ de Conceição do Mato Dentro, no distrito de Córregos, sendo considerado o povoado mais antigo da região.

\subsection{Materiais e métodos}

O Mapa de Danos é a representação gráfico-fotográfica, onde são ilustradas e discriminadas, rigorosa e minuciosamente, todas as manifestações de deteriorações da edificação visando sintetizar o resultado das investigações sobre as alterações estruturais e funcionais nos materiais, nas técnicas, nos sistemas e nos componentes construtivos". (TINOCO, 2009, p.04)

Deste modo, o presente artigo foi elaborado em quatro etapas: levantamento das manifestações patológicas apresentadas, por meio de arquivos fotográficos e relatórios técnicos fornecidos pelo IEPHA-MG; identificação dos danos em plantas arquitetônicas, com auxílio do software AutoCAD; e elaboração do diagnóstico, por meio de uma tabela, utilizando o software Excel, composta por: manifestação patológica, aspecto observado, agente, causa provável e possíveis intervenções; e, desenvolvimento de um gráfico contendo o percentual de incidência de cada uma das manifestações patológicas identificadas na capela, com o auxílio do software Excel.

Paralelamente, realizou-se uma visita técnica a Capela Nosso Senhor de Passos, no dia 24 setembro de 2019, com a presença do Eng. Geraldo e da Arquiteta Helena, representantes legais do IEPHA/MG, e do Sr. Paulo, empreiteiro responsável pela obra, no intuito de compreender o processo e as técnicas de restauro utilizadas na edificação.

Visando o embasamento e sustentação desse trabalho, realizou-se também uma revisão bibliográfica sobre patrimônio histórico, preservação, tombamento, restauro e manifestações patológicas.

\section{RESULTADOS E DISCURSSÕES}

De acordo com o relatório da Século 30 Arquitetura e Restauro (2013), na estrutura da Capela foram identificadas algumas trincas e fissuras, porém era necessário a retirada do reboco para uma melhor avaliação dos danos. O entorno da edificação se encontrava em estado regular, com algumas partes inclinadas, permitindo o escoamento de águas pluviais para o seu interior. $\mathrm{O}$ engradamento da nave e capelas laterais apresentava-se com as peças estruturais em bom estado, porém o ripamento, rufo e beiral dispunha de algumas deteriorações. A cobertura em telhas curvas possuía algumas peças quebradas, faltantes e escorridas, que eram responsáveis pelas goteiras existentes. O piso em cimentado apresentava pontos com umidade, má execução de obra e algumas trincas e fissuras. Os elementos de madeira, pintados em tinta a óleo, na cor azul, assim como as alvenarias em tinta látex branco, o barrado chapiscado, na cor cinza e o verniz do friso, 
apresentava desgastes e desbotamento. Foi observado também, um deslocamento do bonzo no apoio junto a madre do patamar intermediário.

Após a análise e investigação dos danos apresentados, bem como a pesquisa histórica realizada, o estado de conservação da Capela foi considerado irregular, devido a existência de diversas manifestações patológicas por toda a sua extensão, em grau de intensidade variável, e que comprometiam a estrutura e a vida útil da edificação, visto que existia um processo de degradação, devido à falta de manutenção, idade da construção, ataque de insetos xilográficos e ações do intemperismo.

\subsection{Principais manifestações patológicas identificadas}

\subsubsection{Mofo / bolor}

Devido a presença de umidade e escoamento irregular das águas pluvias, o mofo / bolor, caracterizado por manchas esverdeadas ou escuras, é definido por Alucci et al. (1988 apud ANTUNES 2010, P. 67), citado por Silva (2017, p.04), como "uma alteração observável macroscopicamente na superfície de diferentes materiais, sendo uma consequência do desenvolvimento de microrganismos pertencentes ao grupo dos fungos". Recomenda-se a limpeza da superfície com escova e utilização de produtos a base de cloro, bem como a correção da infiltração e do sistema de drenagem.

\subsubsection{Fissuras / trincas}

Oliveira (2012, p.09), define fissuras e trincas como manifestações patológicas geralmente causadas por tensões dos materiais, pois se os mesmos forem solicitados com um esforço maior que sua resistência acontece a falha provocando uma abertura, que é classificada como fissura, trinca, rachadura, fenda ou brecha, de acordo com sua espessura. Além disso, fatores como expansão por absorção de umidade, recalque de fundação, deformações dos componentes estruturais e movimentação térmica, contribuiu para o seu surgimento. Deste modo, torna-se necessário o estudo do solo para adoção de reforços, selagem com material aderente e estabilização dos níveis de umidade, como medidas corretivas.

\subsubsection{Eflorescência}

Caracterizada por manchas brancas, Vitório (2003, p. 51), citado por Lima (2017, p.15), explica que a eflorescência é um depósito de sais que se acumula sobre a alvenaria, que varia de acordo com o tipo de sal que foi depositado, onde toda a água da solução é evaporada, restando apenas o sal, que pode deteriorar a alvenaria devido sua composição química, sendo necessário a sua remoção através de lavagem adequada a partir de produtos específicos.

\subsubsection{Manifestações patológicas na pintura}

Oriundas dos agentes abióticos relacionados as alterações climáticas, espeficicação errônea de materiais e preparo inadequado da superfície, as manifestações patológicas relacionadas à pintura, ocorreram em quatros estágios.

Primeiramente identificou-se a deterioração, através da ausência de uma superfície lisa e limpa, onde Harris (2001 apud HIRT, 2014), completa que é o processo capaz de comprometer o desempenho de uma estrutura ou material.

“Após este estágio, ocorreu o descolamento, de modo a separar uma ou mais camadas dos revestimentos argamassados e apresentam extensão que varia desde áreas restritas até dimensões que abrangem a totalidade de uma alvenaria”. (BAUER, 2010, p. 1), citado por Lima (2017, p.15)

Posteriormente, têm-se o processo de "ruptura na pintura causada pelo desgaste natural do tempo, levando ao total comprometimento da superfície. No estado inicial o problema se apresenta como uma fina fissura e em seguida, num estágio mais avançado, começam a ocorrer as descamações da tinta”. (POLITO, 2006, p.40)

Por fim, "caracteriza-se pela destruição da pintura, que se esfarela, destacando-se da superfície juntamente com partes do reboco”. (CONTI; CASTILHO,2009 apud BRAGA, 2010, p. 69)

Deste modo, propõe-se a realização da raspagem e limpeza da superfície afetada, para refazer o revestimento de maneira adequada, bem como a execução do chapisco, caso seja necessário.

\subsubsection{Vegetação}


Lima (2017, p.15), ainda cita Ripper (2009, p. 239 e 240) para explicar o crescimento de vegetação, pois devido “as sementes, juntamente com a terra carregada em suspensão pelo vento, se depositarem em juntas de dilatação [...] encontram um ambiente propício para desenvolverem, havendo a tendência de suas raízes penetrarem no concreto, danificando-o". Assim sendo, sugere-se a remoção da vegetação, juntamente com a estabilização e reforço da fundação para a correção das aberturas.

\subsubsection{Sujidade}

A sujidade, por Magalhães (2002), citado por Borges, et al. (2014, p.26), consiste no recobrimento dos revestimentos com poeiras, fuligem e outras partículas poluentes existentes em suspensão na atmosfera, cujas principais causas relacionamse com escorrimento da água da chuva nas superfícies, e a orientação da fachada em relação aos principais agentes climáticos (vento e sol). É identificada através de manchas avermelhadas, sendo recomendado a remoção da camada danificada e posterior aplicação de impermeabilizante.

\subsubsection{Deterioração da madeira}

Rodrigues e Sales (2013, p.05), explica que a degradação superficial por apodrecimento, mudança de cor da superfície exposta ao sol ou a luz, empenos das peças por secagem não controlada, e ainda as dilatações ou retrações elevadas da madeira causadas por ajustamentos às condições ambientais em serviço e ataque de insetos xilófagos, provocam aberturas de grandes juntas entre as peças ou empolamentos, sendo elas algumas alterações das características físicas e químicas da madeira. Desta forma, propõe-se a correção de vazamentos, substituição das peças danificadas e utilização de produtos biocidas, como medidas de ação corretiva dos danos.

\subsection{Mapa de Danos e análise das manifestações patológicas identificadas}

A partir do mapeamento de danos, pode-se inferir que não foram evidenciadas atuação de sobrecargas que comprometessem a integridade da estrutura, ou que possam provocar a separação física da edificação. Observou-se que as a degradação da madeira foi a manifestação patologica de maior incidência, seguida da desagregação da pintura, e posteriormente as fissuras e trincas, encontradas principalmente nas fachadas frontal e posterior, devido a constante exposição às variações climáticas e à existência de forças horizontais associadas ao recalque de fundação.

Além disso, no interior da edificação, a maior incidência de deformações plásticas foi encontrada na cobertura, como resultado da existência de telhas partidas, mau funcionamento de caleiras e rufos, pois a umidade é uma das principais causas da manifestação das patologias, uma vez que por meio de ascensão capilar, a água promove o aparecimento de manchas, eflorescências, sais, peeling de pintura de putrefacção, entre outras formas de uso.

Em contrapartida, conclui-se ainda que as fachadas laterais apresenta um melhor estado de conservação, e as manifestações patológicas que se encontravam em menor número eram o descolamento da pintura, a eflorescência e a presença de vegetação. Destacam-se também duas vantagens em relação a sua localização, pois devido a igreja está inserida no distrito de Córregos, povado distante $25 \mathrm{~km}$ da cidade de Conceição do Mato Dentro, em Minas Gerais, bem como por a rua em que a igreja se encontra apresenta um fluxo baixo de veículos, implica em uma minimização da exposição ao vandalismo e, uma menor vibração da estrutura.

É importante salientar que o atual estado da degradação da edificação, é reflexo da ação das condições ambientais aliados ao seu baixo nível de manutenção, tendo em vista que os componentes utilizados na época de sua construção possuem maiores influências dos agentes externos tanto naturais quanto antrópicos.

Com o auxílio dos relatórios fotográficos e descritivos fornecidos pelo IEPHA-MG, elaborou-se o Mapa de Danos da capela, representando as vistas frontal, lateral direita, lateral esquerda e posterior, juntamente com dois cortes o AA e o BB., conforme as figuras 2,3 e 4 . 


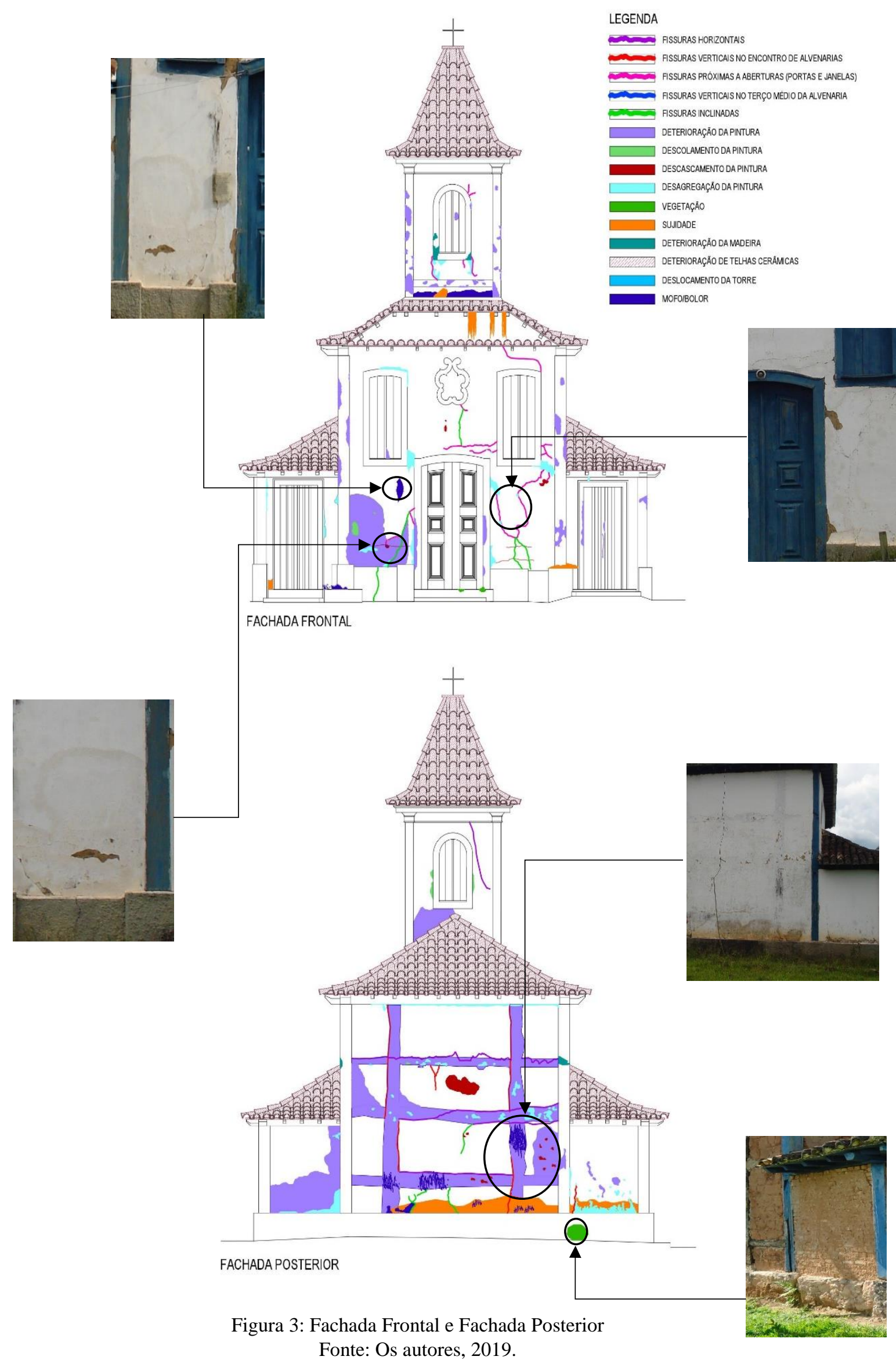




\section{CBPAT 2020

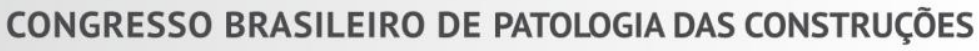 \\ DE 15 A 17 DE ABRIL | FORTALEZA - CE}

ISBN 978-65-86819-05-2
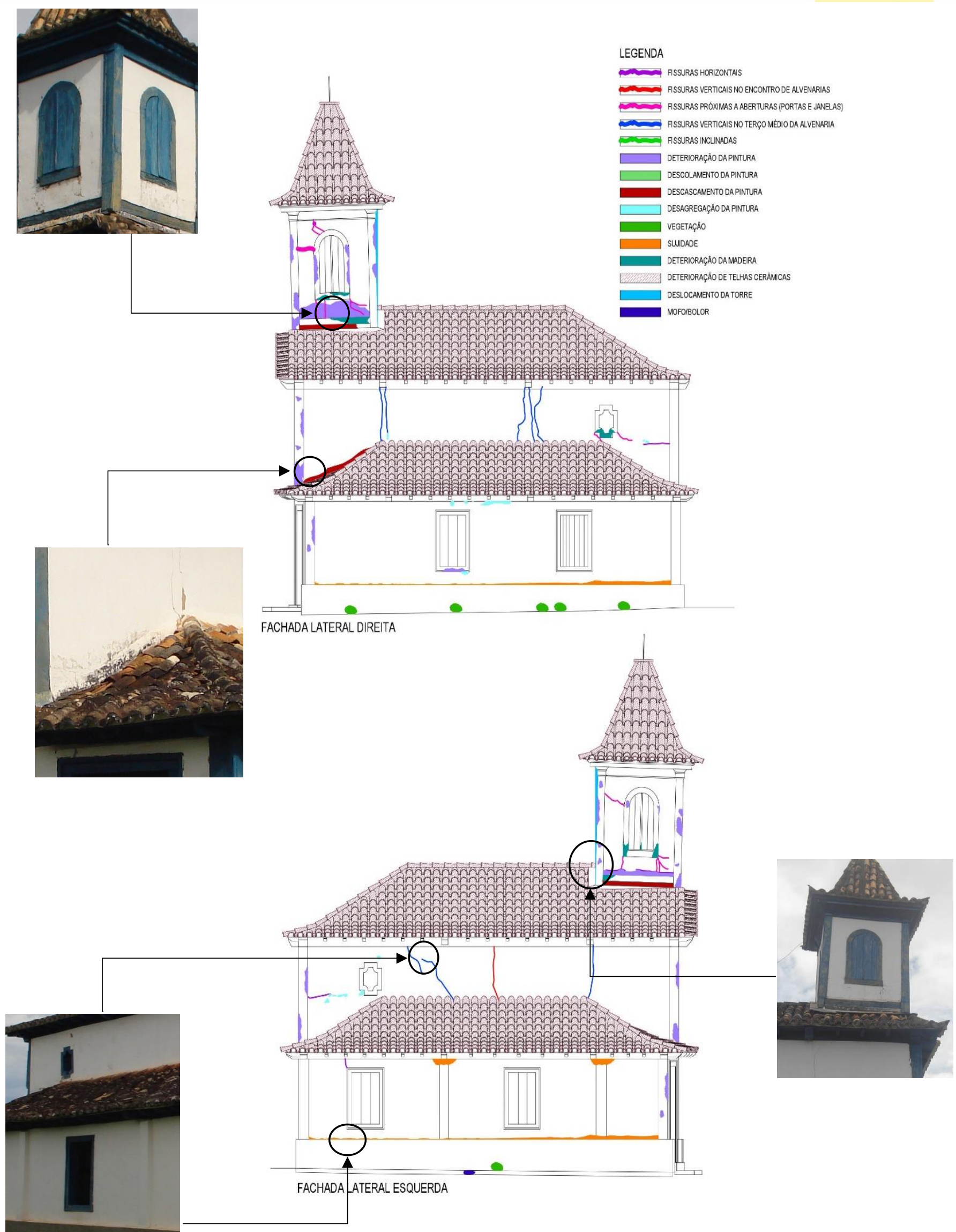

Figura 4: Fachada Lateral Direita e Fachada Lateral Esquerda Fonte: Os autores, 2019. 

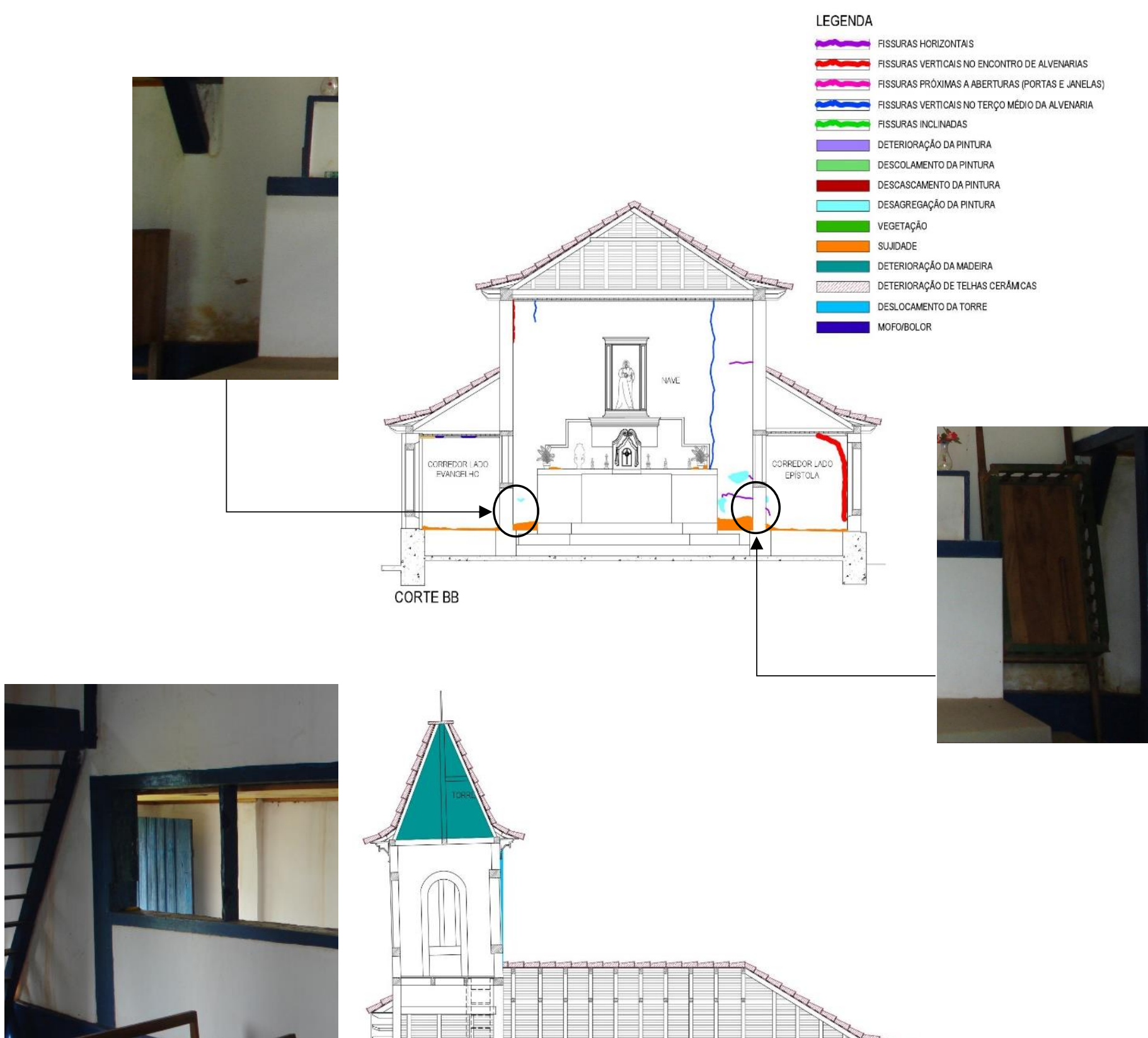

Figura 5: Corte AA e Corte BB

Fonte: Os autores, 2019. 


\section{CONCLUSÃO}

Deste modo, conclui-se que é de vital importância o estudo minucioso das causas de cada ocorrência de anomalia a fim de nortear as medidas a serem tomadas para sua resolubilidade e posterior prevenção, para evitar interferências mais agressivas e contribuir para a manutenção/conservação do bem.

Tendo como embasamento o estudo realizado acerca das manifestações patológicas encontradas tanto nas fachadas quanto no interior da Capela é possível inferir que a maior parte das incidências das manifestações patológicas encontradas foram nos revestimentos das alvenarias, devido principalmente a falta de manutenção da mesma, juntamente com a exposição às intempéries, decorrentes da ação de chuvas, ventos, baixa umidade relativa e aumento da temperatura ambiente, que contribuíram também para a proliferação de fungos e vegetações.

É possível inferir ainda que, os patrimônios tombados, por serem edificações arcaicas, possuem problemas mais graves no que se diz respeito à apresentação de danos, devido por exemplo, aos materiais empregados na época. E que, os mesmos são patrimônios culturais, tornando necessária a implementação de políticas públicas que valorizem a história, marco e potencial que o patrimônio representa para a sociedade.

\section{REFERÊNCIAS}

ARAÚJO, Roberto Antônio Dantas de. Seriam avançadas as principais técnicas construtivas trazidas pelos portugueses no período colonial?. Centro de Estudos Avançados da Conservação Integrada/ UFPE, 2002.

BARAtTo, R. Igreja da Pampulha é reaberta ao público após um ano de restauro. ArchDaily. [S.I.] 2019. Disponível em: <https://www.archdaily.com.br/br/925850/igreja-da-pampulha-e-reaberta-ao-publico-apos-um-ano-derestauro> Acesso em: 20 fev. 2020.

BRAGA, Célia Cavalcanti. Manifestações patológicas em conjuntos habitacionais: A degradação das fachadas. 2010. 158 p. Dissertação (Mestrado em Engenharia Civil) - Universidade Católica de Pernambuco, Recife, 2010.

BRASIL. Constituição da República dos Estados Unidos do Brasil de 1934. Diário Oficial da União: seção 1, Brasília/DF, p. 1, 16 jun. 1934

BRASIL. Lei nº. 378, de 13 de janeiro de 1937. Dá nova organização ao Ministério da Educação e Saúde Pública. Rio de Janeiro/Capital Federal, 1937.

BRASIL. Decreto-lei $\mathrm{n}^{\mathrm{o}} 25$ de 30 de novembro de 1937. Organiza a proteção do patrimônio histórico e artístico nacional. Instituto do Patrimônimo Histórico e Artístico Nacional. Diário Oficial da União: seção 1, Brasília/DF, p. 240560, 6 dez. 1937.

BRITO, L. D.; CALIL JR., C. Técnicas de inspeção visual (NDT) para avaliações das manifestações patológicas na estrutura de madeira roliça da "Ponte Fazenda Yolanda" em São Carlos, Brasil. 17 f. Anais In: IX Congresso Internacional sobre Patología y Recuperación de Estructuras. João Pessoa. 2013.

BRITO, L. D. Patologia em Estruturas de Madeira: Metodologia de Inspeção e Técnicas de Reabilitação. 502 f. Tese (Doutorado em Engenharia de Estruturas) - Departamento de Engenharia de Estruturas, Escola de Engenharia de São Carlos, Universidade de São Paulo. São Carlos. 2014.

CABRAL, Zélio. Apostila noções de administração de recursos materiais. 1ª Edição. Brasil, p. 77, 2017.

CASTRO, Mariângela; FINGUERUT, Sílvia (Org.). Igreja da Pampulha: restauro e reflexões. Rio de Janeiro: Fundação Roberto Marinho, 2006.

Cleide Cristina Caldeira. Conservação Preventiva: histórico. R. CPC, São Paulo, v.1, n.1, p. 91-102, nov. 2005/ abr. 2006. 
Eduardo Ismael Murguia; Silvia Nathaly Yassuda. Patrimônio histórico-cultural: critérios para tombamento de bibliotecas pelo IPHAN. Perspectivas em Ciência da Informação, v.12, n.3, p. 65-82, set./dez. 2007.

Elianne Auxiliadora Moreira Borges, et al. Mapeamento de danos em monumento histórico Art Déco. REEC - Revista Eletrônica de Engenharia Civil, v. 8, n. 03, p.20-37, 2014.

Esequiel Mesquita; Esmeralda Paupério; António Arêde; Humberto Varum. Boletim Técnico 11: Carcaterização, avaliação e recuperação estrutural de construções históricas. ALCONPAT, Mérida - México, dezembro de 2015.

Hely Lopes Meirelles. Tombamento e indenização. Revista Direito Administrativo, Rio de Janeiro, v.161, p.1-6, jul./set. 1985.

HIRT, Bruno Francisco. Manifestações patológicas em obras de escolas públicas estaduais do Paraná. 2014.48 f. Trabalho de Conclusão de Curso (Especialização) - Universidade Tecnológica Federal do Paraná, Curitiba, 2014.

ICOMOS. Icomos Charter- Principles for the analysis, conservation and structural restoration of architectural heritage. In: International Council on Monuments and Sites. Anais.Thessalonik, 2003.

Instituto Estadual do Patrimônio Histórico e Artístico de Minas Gerais. IEPHA. 2016. Página Inicial. Disponível em: <http://www.iepha.mg.gov.br/>. Acesso em 01 out. 2019

Jorge Eduardo Lucena Tinoco. Mapa de Danos Recomendações Básicas. CECI: Centro de Estudos Avançados da Conservação Integrada. Olinda, v.43, série 2, p. 03-21, 2009.

LEMOS, Carlos Alberto Cerqueira. Arquitetura brasileira. São Paulo: Melhoramentos: Ed. Da Universidade de São Paulo, 1979.

LIMA, Flávia Roberta Roque. Levantamento de patologias na alvenaria: Fissuras, eflorescências e umidade. 2017. 39 fls. Trabalho de Conclusão de Curso (Graduação em Engenharia Civil) - Faculdade Pitágoras, Londrina, 2017.

LIMA, G. E. S. L.; SOUZA, K. D.; TIBIRIÇÁ, A. C. G. Investigação e Diagnóstico de Patologias Relacionadas às fachadas de uma edificação. XV Encontro Nacional de Tecnologia do Ambiente Construído. Viçosa: UFV, 2014.

Toshio Mukai. A Degradação do Patrimônio Histórico e Cultural. Revista Direito Administrativo. Rio de Janeiro, 234 : 33-41, out./dez. 2003.

OLIVEIRA, Myriam Andrade Ribeiro de. Arquitetura da mineração nos estados de Minas Gerais e Goiás. In: Arquitetura na formação do Brasil. Brasília: UNESCO, Instituto do Patrimônio Histórico e Artístico Nacional, 2008.

POLITO, Giulliano. Principais Sistemas de Pinturas e suas Patologias. Belo Horizonte: UFMG, Faculdade de Engenharia 2006.

RODRIGUES, M. A. S.; SALES, J. C. A madeira e suas patologias Estudo de caso: Igreja Nossa Senhora das Mercês - Itapipoca/CE. 15fls. IX Congresso Internacional sobre Patología y Recuperación de Estructuras. João Pessoa. 2013.

SILVA, Anderson José da. Análise de mapa de danos das fachadas de igrejas históricas tombadas localizadas no município de Jaboatão dos Guararapes. 2017. 18 f. Trabalho de Conclusão de Curso (Tecnólogo em Construção Civil - Edificações) - Universidade Federal Rural de Pernambuco, Cabo de Santo Agostinho, 2017

STARLING, Otávio Augusto de Sá. Igrejinha da Pampulha: Descritivo Histórico das Intervenções e Estado de Conservação Atual. Belo Horizonte: UFMG, Escola de Arquitetura, 2018. 